\title{
A SYNTACTICAL STRUCTURE ANALYSIS OF METAPHORS IN THE TRANSLATION OF LAYLA MAJNUN'S ROMANCE IN 2002
}

\author{
Elita Ulfiana ${ }^{1}$ \\ ${ }^{1}$ UIN Raden Mas Said Surakarta \\ 12elita.ulfiana@iain-surakarta.ac.id
}

\begin{abstract}
The purpose of this study is to describe the syntactic structure in the metaphors in Layla Majnun's translation of the novel. The data was obtained from the novel Layla Majnun published by Navila through listening with simak bebas libat cakap technique. Data analysis was padan using pilah unsur tertentu method, namely by sorting certain elements using referential sorting. The results showed that the metaphorical structure in Layla Majnun's novel was dominated by phrases and clauses. Images in the structure of phrases and clauses are displayed through the categories of nouns and verbs. The form of the verb in the clause is found in the form of action verbs, events and circumstances. The variety of these forms proves that the metaphorical structure is consistent in constructing its construction to form a concrete meaning that is easily understood by the reader.
\end{abstract}

Keywords: Metaphor, Sintax, Roman Layla Majnun

$$
\begin{aligned}
& \text { ملخص } \\
& \text { يهدف هذا البحث إلى وصف التراكيب النحوية فن استعارات ترجمة قصة حب ليلى مجنون. بيانات البحث }
\end{aligned}
$$

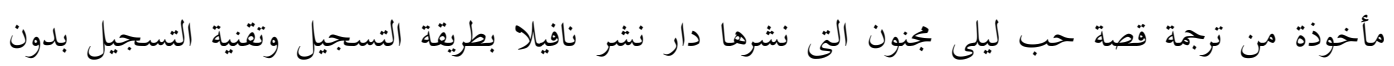

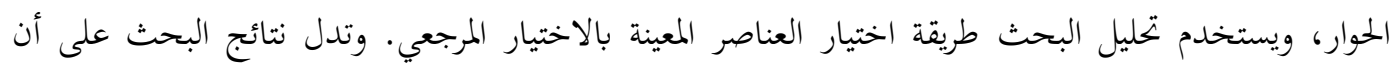

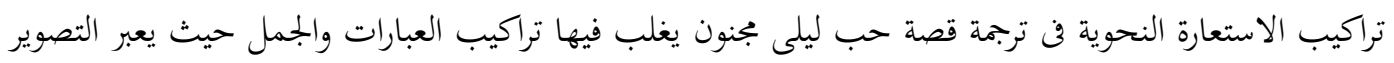

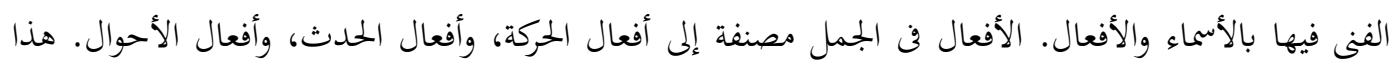

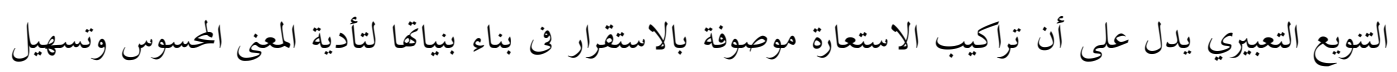

$$
\begin{aligned}
& \text { إرسال الرسالة إلى القراء. }
\end{aligned}
$$$$
\text { الكلمات المفتاحية: الاستعارة، النحو، قصة حب ليلى مجنون. }
$$

\section{A. Pendahuluan}

Metafora sering dijumpai pada komunikasi baik secara lisan maupun tertulis. Dalam realitas kehidupan, metafora merupakan bentuk kearifan makna dalam berbahasa dan sebagai bentuk ekspresi untuk mengungkapkan perasaan (Setiaji, A. B., Jufri, J., \& Nensilianti, 2018). Dalam bidang linguistik, (Knowles, 2005) menjelaskan bahwa metafora ditemukan di berbagai wacana seperti politik, olahraga dan periklanan. Sementara itu, metafora pada bidang sastra ditampilkan melalui fiksi dan puisi. Salah satu metafora yang ditampilkan melalui fiksi yaitu dapat ditemui dalam roman yang berjudul Layla Majnun karya Syaikh Nizami.

Di dalam roman Layla Majnun pengarang banyak menghadirkan metafora untuk mewakili pikiran dan perasaannya. Metafora diciptakan untuk mewakili suatu konsep yang ada dipikiran penulis agar pembaca dapat memahami suatu konsep 
yang dimaksud oleh pembaca, metafora dapat memunculkan makna baru, dan metafora diungkapkan secara langsung tanpa menggunakan tanda penghubung (seperti, bak, bagaikan). Metafora memilih unsur citra (kias) yang kemiripan atau kesamaannya bersifat konkret dan berada di luar bahasa. Selain itu, metafora juga memiliki keindahan majas dan dapat menambah perbendaharaan peribahasa (Arianto, 2018), seperti pada data roman Layla Majnun berikut ini:

(1) Tetapi Layla? Rembulan Arab itu harus tersenyum pada orangorang di sekitarnya, agar tidak di cap angkuh, dan demi melindungi martabat keluarganya (LM, 2001:74). Metafora rembulan Arab pada kalimat (1) merupakan metafora nominatif subyektif dengan pola $\mathrm{N}+\mathrm{N}$. Dengan pola $\mathrm{N}+\mathrm{N}$ membuktikan bahwa metafora yang digunakan dalam syair roman Layla Majnun menggunakan citra nomina untuk mengungkapkan secara langsung secara konkret kemiripan makna yang ingin disampaikan sehingga makna dari metafora dapat dipahami. Pada metafora Rembulan Arab di atas, makna kias dalam konteks roman Layla Majnun adalah wanita Arab yang cantik seperti rembulan. Penulis memberikan bandingan secara langsung dan konkret yaitu rembulan. Kecantikan perempuan Arab itu seperti keindahan yang terdapat pada rembulan di malam hari. Contoh metafora dalam syair tersebut menunjukkan bahwa metafora merupakan ungkapan secara langsung untuk mewakili konsep penulis agar pembaca dapat memahami konsep yang dimaksud penulis. Oleh karena itu, analisis struktur fungsional menjadi hal yang penting dilakukan dalam penelitian ini untuk mengetahui struktur sintaksis metafora yang digunakan oleh penulis dalam membuat syair pada Roman Layla Majnun.

\section{B. Kerangka Teori dan Konsep Dasar Metafora}

Ada banyak alasan mengapa masyarakat penutur bahasa menggunakan metafora dalam pembicaraan atau penulisan. Hal ini disebabkan oleh tidak ada kata lain untuk merujuk pada hal tertentu tersebut. Ada beberapa alasan masyarakat penutur bahasa menggunakan metafora, yaitu untuk mewakili suatu konsep yang ada dipikiran penutur agar lawan tutur dapat memahami suatu konsep yang dimaksud oleh penutur. Konsep atau objek yang dipilih berdasarkan kias atau persamaan (Kridalaksana, 2008). Metafora "surat kilat" menyatakan bahwa surat yang dikirim harus secepat mungkin. Citra "kilat" merepresentasikan suatu pengalaman masyarakat penutur yang digunakan untuk memberikan makna baru terhadap satuan ekspresi suatu kebahasaan. Menurut (Knowles, 2005) melalui metafora, masyarakat penutur bahasa dapat mengungkapan sesuatu yang maknanya sulit dipahami (abstrak) akan menjadi lebih mudah dipahami (konkret). Sehingga dapat disimpulkan bahwa metafora merupakan gaya bahasa atau ungkapan yang secara langsung tanpa menggunakan kata penghubung (bak, bagaikan, seperti) untuk mengungkapkan sesuatu yang ingin disampaikan dengan makna baru yang lebih konkret.

\section{Komponen Unsur Metafora}

Metafora diyakini oleh para penutur bahasa sebagai sarana puitika dan retorika yang dapat diungkapkan melalui kata, frasa, klausa dan kalimat. Konsep atau pola dalam menganalisis metafora, yaitu adanya topik yang dibicarakan, citra atau topik kedua dan sense (Parera, 2004). Topik merupakan butir makna yang dilukiskan dalam metafora atau hal yang dibicarakan. Unsur yang kedua adalah citra yang berarti kejadian, proses, hal yang dipakai sebagai bandingan. Unsur citra menjadi bandingan bagi topik dan sebagai bahan kreativitas penulisnya (Setiaji, 2019). Unsur yang ketiga adalah sense atau titik kemiripan antara objek dan citra terdapat aspek-aspek khusus yang mempunyai kemiripan. Sebagai contoh "Ia adalah mahkota bangsa Arab, yang dipuja dan dikenang selalu". Unsur objek pada metafora tersebut adalah "Ia" dan unsur citranya (citra) pada metafora tersebut adalah "mahkota" sedangkan sense atau titik kemiripan antara objek 
dengan citra adalah "seseorang yang dihargai, dijunjung tinggi dan dicintai". Tiga unsur di atas merupakan unsur-unsur yang wajib hadir pada penciptaan sebuah metafora untuk mengetahui makna yang terkandung di dalam metafora.

\section{Pola Fungsional Sintaksis pada Metafora}

Pada tataran sintaksis, metafora diklasifikasikan menjadi tiga bagian, yaitu metafora nominatif, metafora predikatif dan metafora kalimatif (Wahab, 1991). Pada metafora nominatif, dapat dibagi lagi menjadi dua bagian, yaitu metafora nominatif subjektif dan metafora nominatif objektif. Adapun pengertian dari metafora nominatif subjektif adalah metafora yang berpola nomina dengan lambang kiasnya berada pada fungsi subyek kalimat sedangkan metafora nominatif objektif merupakan metafora yang berpola nomina dengan lambang kiasnya berada pada fungsi objek kalimat. Klasifikasi pembagian fungsi sintaksis kedua adalah metafora predikatif. Pada metafora predikatif, unsur kiasnya berada pada fungsi predikat dalam kalimat. Klasifikasi pembagian fungsi sintaksis ketiga adalah metafora kalimatif. Pada metafora kalimatif, lambang kiasnya tidak terbatas pada subjek atau predikat saja tetapi seluruh fungsi yang ada pada kalimat.

\section{Hasil dan Pembahasan}

\section{Metafora Bentuk Frasa dalam Roman Layla Majnun}

Dari segi struktur metafora roman Layla Majnun dapat diungkapkan dalam bentuk frasa dan klausa untuk menyatakan kesamaan dengan sesuatu yang diperbandingkan (Mahur, 2019). Pada pola frasa ditemukan frasa nomina dan perluasan frasa. Frasa Nominal adalah frasa yang memiliki komponen nomina (Chaer, 2015). FN terdiri atas beberapa unsur yang berbeda, antara lain: FN yang berpola $\mathrm{N}+\mathrm{N}$ dan $\mathrm{FN}$ berpola $\mathrm{N}+\mathrm{V}$. Di dalam roman Layla Majnun terdapat FN berpola $\mathrm{N}+\mathrm{N}$ dan FNS yang berpola $\mathrm{N}+\mathrm{V}$. berikut ini adalah frasa nominal yang berpola $\mathrm{N}+\mathrm{N}$ dalam roman Layla Majnun.

\subsection{Frasa Nominal $\mathbf{N}+\mathbf{N}$}

Metafora dalam roman Layla Majnun berstruktur Frasa Nomina (FN) dengan pola Nomina+Nomina $(\mathrm{N}+\mathrm{N})$ yang mempunyai makna gramatikal "seperti". Perbandingan yang digunakan berturut-turut menggunakan citra berkategori kata nomina dengan ciri komponen nomina $(\mathrm{N})$ pertama (+ciri, sifat, keadaan khas) sedangkan $\mathrm{N}$ kedua juga memiliki komponen (+ciri, sifat, keadaan khas). Penggunaan $\mathrm{N}$ pada unsur atribut sebagai citra berkategori kata nomina konkret. Artinya, wujud kata bendanya menggambarkan suatu objek yang dapat dilihat atau dikenali dengan panca indra. Jenis nomina konkret dapat berupa makhluk hidup, benda mati, tempat.

FN yang bersturktur $\mathrm{N}+\mathrm{N}$ dapat dilihat dalam data kalimat berikut.

(1) Cahaya gadis itu benar-benar mempesona, jikalau matahari tidak terbit, cukuplah wajah Layla yang menggantikan sinarnya $(L M, 2001: 10)$.

(2) Cahaya cinta mereka tidak pernah mati (LM, 2001:82).

Metafora cahaya gadis dan cahaya cinta pada data (1) dan data (2) merupakan metafora yang berstruktur frasa. $\mathrm{N}$ pertama sebagai citra atau lambang kiasnya berjenis kata benda nomina konkret cahaya yang dapat dilihat oleh panca indra. Walaupun pada $\mathrm{N}$ kedua data (2) berwujud konkret, $\mathrm{N}$ pertama cahaya memberikan makna yang lebih spesifik untuk mendapatkan pemahaman makna dari metafora tersebut. Selain itu, dalam memahami makna, maka metafora tersebut dilihat secara keseluruhan dalam konteks kalimat yang melatarbelakangi penggunaannya (Mahur, 2019). Cahaya pada data (1) dapat dimaknai sebagai sinar atau terang, namun bukan dimakna sebagai sinar dari matahari, bulan atau lampu. Sinar dalam gadis tersebut berarti kejernihan yang terpancar dari wajah yang dapat dilihat oleh panca indra, sedangkan $\mathrm{N}$ pertama cahaya pada data (2) dapat dimaknai sebagai sinar yang terang seperti matahri atau bulan yang sinarnya abadi tidak pernah mati. 
Selain FN berpola $\mathrm{N}+\mathrm{N}$ di atas di dalam roman Layla Majnun juga ditemui FN berpola $\mathrm{N}+\mathrm{N}$ lainnya, seperti dapat diihat pada kalimat berikut.

(3) Di wajahnya tergambar jelas badai kemarahan yang lebih hebat dari letusan gunung berapi (LM, 2001:68).

(4) Engkau adalah segalanya bagiku, karena bibit cinta yang engkau taburkan telah berakar dalam hatiku (LM, 2001:151).

(5) Kemudian aku memutuskan untuk tinggal bersamamu, mencercap hikmah dari akar jiwamu (LM, 2001:174).

Pada metafora data (3) badai kemarahan, (4) bibit cinta dan (5) akar jiwamu berturut-turut $\mathrm{N}$ pertama berjenis kata benda konkret. Badai, bibit dan akar sebagai citra dapat dilihat dengan panca indra. Badai pada data (3) dimaknai sebagai cuaca buruk dengan angin yang kencang memberikan makna konkret terhadap penggambaran $\mathrm{N}$ kedua marah. Begitu pula pada $\mathrm{N}$ kedua data (4) bibit dan (5) akar merupakan bagian dari tumbuhan yang dapat dilihat oleh panca indra memberikan makna konkret terhadap $\mathrm{N}$ kedua data (4) cinta dan (5) jiwamu. Bibit dimaknai sebagai benih yang dapat dikembangkan dipilih untuk mengkonkretkan $\mathrm{N}$ kedua cinta. Cinta yang tidak dapat ditangkap oleh panca indra seolah-olah diwujudkan dalam bentuk konkret dengan hadirnya $\mathrm{N}$ pertama benih sehingga definisi cinta dapat dengan mudah digambarkan melalui pembading N pertama benih. Pada data (5) akar dimaknai sebagai bagian tumbuhan yang tertanam di tanah sebagai penguat dipilih untuk memberikan makna konkret terhadap $\mathrm{N}$ kedua jiwa. Jiwa yang tidak dapat dilihat oleh panca indra diberi bandingan $\mathrm{N}$ akar sebagai citra untuk menggambarkan keadaan jiwa yang kuat dalam diri manusia.

(6) Kerudung kesuraman malam berganti dengan pandangan yang menyejukkan dari fajar keperakan ( $L M, 2001: 83)$.

(7) "Anakku! Cinta yang engkau rasakan telah membuatmu menjadi begini! Menjauhkanmu dari rumah, memberimu selendang sakit hati dan pakaian keputusasaan (LM, 2001:160).

Pada data (6) dan (7) terdapat metafora FN kerudung kesuraman dan pakaian keputusasaan. $\mathrm{N}$ pertama sebagai citra berjenis nomina konkret benda mati yaitu kerudung dan pakaian yang dapat dipadang melalui panca indera. Kedua nomina konkret tersebut membantu memperjelas makna dari yang dibicarakan dalam metafora tersebut yaitu mengenai kesuraman dan keputusasaan. $\mathrm{N}$ kedua pada masing-masing data (6) dan (7) yang dinilai abstrak, akan menjadi jelas maknanya jika dibandingkan dengan hal yang konkret. N pertama data (6) kerung yang berarti kain penutup kepala perempuan ketika melekat pada $\mathrm{N}$ kedua kesuraman dapat dimaknai mengenai kehidupan yang susah ibarat kerudung yang selalu melekat pada dirinya dan pakaian yang berarti barang yang dapat dipakai dibandingkan menjadi makna yang seakan-akan suatu keputusasaan dalam arti hilangnya arah tujuan hidup sekarang menjadi hal yang sedang dialami dalam dirinya.

\subsection{Frasa Nominal $N+V$}

Selain Frase Nomina Konkret (FNK) berpola $\mathrm{N}+\mathrm{N}$ di dalam roman Layla Majnun juga ditemukan Frase Nomina Tindakan (FNT) yang berpola Nomina+Verba $(\mathrm{N}+\mathrm{V})$. Komponen pertama berupa nomina dan komponen kedua berupa verba di dalam frase. Berikut ini adalah FNT yang berpola $\mathrm{N}+\mathrm{V}$ dalam roman Layla Majnun. Perhatikan kalimat berikut.

(8) Batin menjerit tubuh binasa (LM, 2001: 116).

(9) Dengan suara menyayat, yang terdegar lebih menyedihkan dari sangkakala maut, Layla berkata, "Apakah engkau berharap bisa memilikiku? Wahai tuan sadarilah, perkawinan ini adalah keinginan ayahku, bukan keinginanku sendiri! Aku tidak ingin melakukan 
perbuatan yang aku benci (LM, 2001:123).

Pada data (8) dan (9) merupakan metafora FNT berpola $\mathrm{N}+\mathrm{V}$. Kedua data (8) dan (9) $\mathrm{N}$ pertama berupa $\mathrm{N}$ dan $\mathrm{N}$ kedua sebagai citra berupa tindakan yang dikategorikan dalam V. Batin yang dimaknai sebagai perasaan hati yang tidak dapat dilihat melalui panca indra dapat secara konkret dirasakan melalui indra pendengar dengan bandingan menjerit yang dapat dimaknai sebagai perasaan yang sangat tersakiti, melalaui bandingan menjerit yang merupakan tindakan menjerit atau mengeluarkan suara keras karena tersakiti. Begitu pula dengan bandingan tindakan $\mathrm{V}$ menyayat yang berarti menguliti atau mengiris tipis-tipis seolah-olah dilakukan untuk menggambarkan diri yang merasa sedih dan tersakiti yang digambarkan melalui suara yang terjeda-jeda (terpotongpotong).

\subsection{Perluasan Frasa Nominal}

Sebuah frasa dapat diperluas baik dengan kata maupun frase lain. Perluasan FN dalam penelitian ini dapat diperluas dengan kata yang (Chaer, 2015). Kata yang merupakan kata yang dapat disisipkan pada frasa yang bertujuan untuk memperjelas makna (Sasangka, 2014). Di dalam roman Layla Majnun terdapat metafora berstruktur FN yang mengalami perluasan dengan kata yang. Berikut ini deskripsi mengenai perluasan metafora FN dengan kata yang.

(10) Demikian pula nasib yang mengintai dua taruna itu ( $L M$, 2001:15).

(11) Namun jiwaku yang telah terbakar rindu belum sembuh jua (LM, 2001:42).

(12) Kuatkanlah jiwanya supaya dapat menjaga cinta yang telah kamu semaikan (LM, 2001:6162).

(13) Kelahiran Qays, nama bayi itu, membuat semangat hidup Syed Omri yang telah bertahun-tahun padam, kembali bergairah ( $L M$, 2001:5).

Pada data (10) sampai dengan data (11) nasib yang mengintai, jiwaku yang telah terbakar, langit yang menuntunku dan semangat hidup syed Omri yang telah bertahun-tahun padam merupakan metafora FN dengan perluasan kata yang. Perluasan tersebut justru memperjelas hal yang dibicarakan dalam metafora tersebut. Pada data (10) Hal yang dibicarakan adalah nasib yang dimaknai sebagai makna abstrak yaitu ketetapan dari Tuhan atau takdir disandingkan dengan citra mengintai dengan dijembatani dengan kata yang seolah-olah nasib atau tadir menjadi benda hidup yang dapat mengamat-amati grak gerik manusia. Begitu pula pada data (11) jiwaku, (12) cinta, (13) semangat merupakan hal yang dibicarakan. Ketiga data tersebut akan menjadi lebih konkret dengan perluasan kata yang sebagai penghubung citranya (11) terbakar, (12) semaikan, (13) padam.

\section{Metafora Bentuk Klausa dalam Roman Layla Majnun}

Klausa merupakan satuan gramatikal yang terdiri atas beberapa kata dengan ciri sekurang-kurangnya wajib hadir subyek dan predikat (Alwi, H, 2017; Sasangka, 2014). Kedudukan predikat inilah yang dapat menentukan hadirnya fungsi subjek (S), objek (O) maupun pelengkap (Pel). Berikut ini merupakan metafora yang ada dalam roman Layla Majnun dengan struktur klausa.

(14) Jiwanya menjerit, memanggil nama Layla kekasih yang direnggut dari tangannya ( $L M$, 2001:16).

Data metafora (14) jiwanya menjerit terdiri atas dua fungsi dalam struktur klausa yaitu sebagai berikut.

$$
\begin{aligned}
& \text { (14) } \frac{\text { Jiwanya }}{\mathrm{S}} \quad \frac{\text { menjerit }}{\mathrm{P}} \\
& \text { (+manusia) (+manusia) } \\
& \text { (+keadaan) (+kejadian) }
\end{aligned}
$$

Hal yang dibicarakan adalah jiwanya menduduki fungsi $\mathrm{S}$ dan citranya menduduki fungsi P. Hadirnya metafora berstuktur klausa memberikan kemudahan bagi pembaca untuk memahami makna dari metafora tersebut. Hal tersebut disebabkan adanya penunjukan referen secara langsung melalui subyek dan diperjelas dengan citra yang konkret melalui fungsi $\mathrm{P}$ dengan kelas kata verba 
tindakan menjerit. Perhatikan contoh data lain dalam metafora bentuk klausa data di bawah ini.

(15) Padahal hatinya telah dimangsa oleh kesedihan (LM, 2001:149)

Identifikasi pada kalimat (15) metafora berstruktur klausa sebagai berikut:

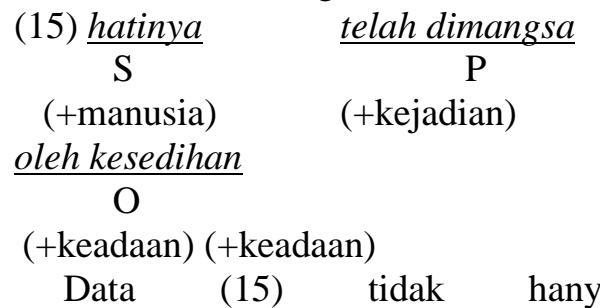
menghadirkan fungsi $\mathrm{S}$ dan $\mathrm{P}$ saja, hadirnya fungsi $\mathrm{O}$ menjadikan makna metafora semakin mudah dipahami. Fungsi $\mathrm{S}$ hatinya merupakan hal yang dibicarakan sedangkan citranya adalah fungsi $\mathrm{P}$ dan $\mathrm{O}$ dengan makna bahwa seolah-olah kesedihan menjadi makhluk hidup seperti hewan yang dapat memangsa hati manusia.

Selain menghadirkan fungsi S, P, dan $\mathrm{O}$, hadir juga fungsi Pelengkap dalam sebuah klausa. Berikut ini contoh data yang menunjukan hadirnya fungsi Pelengkap dalam klausa sebuah metafora.

(16) Hatinya telah terkunci rapat, dan Majnunlah yang memegang anak kuncinya ( $L M, 2001: 122)$.

Identifikasi metafora pada data (18) sebagai berikut:

(16) $\frac{\text { Hatinya }}{\mathrm{S}} \frac{\text { telah }}{\mathrm{P}} \frac{\text { terkunci }}{\mathrm{P}}$ (+manusia) (+keadaan)

rapat

Pel

(+keadaan)

Seperti pada data (15), hadirnya fungsi Pel pada sebuah klausa dalam metafora tersebut memperjelas makna yang ingin disampaikan kepada pembaca. Fungsi S sebagai hal yang dibicarakan dan fungsi P dan Pel sebagai citranya. Hatinya digambarkan dengan perbandingan seperti benda mati yang dapat dikunci yang memberikan makna bahwa perasaan seseorang yang sulit untuk menerima kehadiran seseorang dalam kehidupannya.

\subsection{Kategori Kata Pengisi Predikat dalam Metafora bentuk Klausa}

Klausa dapat digolongkan menjadi empat golongan berdasarkan kategori kata atau frasa yang menduduki fungsi predikat, yaitu kalusa nominal, klausa verbal, klausa bilangan, dan klausa depan (Firman, D., 2016). Untuk membuktikan bahwa dalam konstruksi klausa khususnya pengisi $\mathrm{P}$ merupakan citra yang memperjelas makna dalam memahami sebuah metafora pada bentuk klausa, maka temuan data menunjukan sekurangkurangnya ditemukan dua kategori pengisi $\mathrm{P}$ dalam konstruksi klausa, yaitu klausa nominal dan klausa verbal.

\subsubsection{Klausa Nominal}

Di dalam roman Layla Majnun ditemukan klausa nomina, seperti pada data berikut:

(17) Cinta dan kekayaan adalah bunga kehidupan terindah, yang mampu menggetarkan perasaan $(L M, 2001: 3)$.

(18) Ia adalah mahkota bangsa Arab, yanng dipuja dan dikenang selalu ( $L M, 2001: 10)$.

(19) Bagi pecinta hambatan adalah pupuk yang dapat menyuburkan bunga cinta yang mereka tanam (LM, 2001:16).

Pada data (17) sampai dengan (19) yaitu Cinta dan kekayaan adalah bunga kehidupan terindah, Ia adalah mahkota bangsa Arab, hambatan adalah pupuk yang dapat menyuburkan bunga cinta yang mereka tanam merupakan metafora bentuk klausa nominal. Identifikasi dari pola klausa nomina dalam roman Layla Majnun sebagai berikut:

Tabel 1. Klausa Nomina

\begin{tabular}{|l|l|l|}
\hline \multirow{4}{*}{$\begin{array}{l}\text { Frase pada kalimat } \\
(17),(18),(19)\end{array}$} & $\begin{array}{l}\text { Cinta dan } \\
\text { kekayaaan }\end{array}$ & adalah bunga kehidupan terindah \\
\cline { 2 - 3 } & Ia & adalah mahkota bangsa Arab \\
\cline { 2 - 3 } & Hambatan & $\begin{array}{l}\text { Adalah pupuk yang dapat menyuburkan } \\
\text { bunga cinta yang mereka tanam. }\end{array}$ \\
\hline
\end{tabular}




\begin{tabular}{|l|l|l|}
\hline Fungsi & S & P \\
\hline Kategori & Nomina & Nomina \\
\hline
\end{tabular}

Berdasarkan identifikasi metafora berbentuk klausa nominal pada tabel di atas, ditemukan kopula yang berupa adalah. Hadirnya kopula adalah memberikan suatu jembatan penjelas dalam kontruk metafora, yaitu antara hal yang dibicarakn dengan citranya. Pada data (17) cinta dan kekayaan adalah bunga kehidupan terindah, jika dilihat dari dalam tabel, hal yang dibicarakan yaitu Cinta dan kekayaan mengisi fungsi $S$ dengan kategori kata nomina. selain itu, citranya pun yang mengisi fungsi $P$ menggunakan kategori kata nomina yaitu bunga. Begitu pula pada data (18) dan (19) masing-masing mempunyai fungsi $\mathrm{S}$ dan $\mathrm{P}$ dengan kategori kata nomina. Hal yang menjadi pembeda dengan bentuk frasa, di dalam konstruk klausa, citranya tidak hanya terdiri dari satu kata atau dua kata saja, tetapi diisi oleh beberapa kata sebagai penjelas makna dari sebuah metafora.

\subsubsection{Klausa Verbal}

Klausa verbal merupakan. Dalam penelitian ini ditemukan adanya jenis klausa verbal tindakan, klausa verba kejadian, dan klausa verbal keadaan. Ketiga jenis klausa verbal tersebut menggambarkan hal yang dibicarakan dalam fungsi $\mathrm{S}$ menjadi lebih dipahami dan mengkonkretkan hal yang abstrak melalui penggambaran benda mati seolaholah menjadi makhluk hidup.

\subsubsection{Klausa Verbal Tindakan}

Klausa verbal tindakan tak bersasaran dapat disusun dari sebuah verbal yang memiliki komponen makna (+tindakan) dan (-sasaran). Fungsi dalam klausa tersebut hanya terdiri dari fungsi $S$ dan fungsi P. Di dalam roman Layla Majnun ditemukan metafora berbentuk klausa verbal tindakan tak bersasaran yang dihadirkan melalui fungsi P. Berikut ini merupakan data metafora yang berbentuk klausa verbal tindakan tak bersasaran.

(20) Tampaknya petaka mulai mengintip dan siap merenggut kebahagiaan keduanya (LM, 2001:15).

(21) Demikian pula Majnun, walau jiwanya ingin terus berkelana, namun tubuhnya tak lagi memiliki kekuatan, kakinya tak lagi berdaya $(L M, 2001: 45)$

Pada data (20) sampai dengan (21) petaka mulai mengintip dan jiwanya ingin terus berkelana merupakan klausa verbal tindakan tak bersasaran. Berikut adalah identifikasi dari klausa verbal tindakan tak bersasaran.

Tabel 2. Klausa Verbal Tindakan Tak Bersasaran

\begin{tabular}{|l|l|l|}
\hline $\begin{array}{l}\text { Klausa verba tak } \\
\text { bersasaran pada kalimat } \\
(20) \text { dan }(21)\end{array}$ & Petaka & Mulai mengintip \\
\cline { 2 - 3 } & Jiwanya & Ingin terus berkelana \\
\hline Fungsi & S & P \\
\hline Komponen makna & + manusia & $\begin{array}{l}\text { +manusia } \\
\text { +tempat }\end{array}$ \\
\hline
\end{tabular}

Klausa verbal tindakan tak bersasaran pada data (20) dan (21) diketahui bahwa fungsi $\mathrm{P}$ berkategori verba tindakan yaitu mengintip dan berkelana yang emmiliki komponen +tindakan dan -sasaran. Kedua jenis verba tindakan tersebut memberikan makna yang konkret dan komponen maknanya harus sejalan dengan komponen makna pada fungsi S. Petaka dan Jiwa yang dimaknai sebagai hal yang abstrak tidak dapat dilihat oleh panca indra seolah-olah hidup dan beraktivitas atau sedang melakukan tindakan seperti manusia. 
Selain terdapat klausa verbal tindakan tak bersasaran, metafora di dalam roman Layla Majnun juga terdapat bentuk klausa verbal tindakan bersasaran. Klausa verba tindakan bersasaran merupakan klausa verbal yang memiliki komponen makna (+tindakan) dan (+sasaran). Klausa verba tindakan bersasaran selain menghadirkan fungsi $S$ dan $\mathrm{P}$, hadir juga fungsi lainnya yaitu $\mathrm{O}$. dalam hal ini komponen $\mathrm{V}$ pada fungsi $\mathrm{P}$ harus sejalan dengan komponen makna yang dimiliki oleh fungsi $\mathrm{S}$ dan $\mathrm{O}$. Berikut ini merupakan data metafora berbentuk klausa verbal tindakan bersasaran.

(22) Kesedihan telah memakan ulam dan jantung, tubuhnya tak mampu lagi menahan derita jiwa $(L M, 2001: 137)$.

Pada data (22) Kesedihan telah memakan ulam dan jantung merupakan metafora yang berbentuk klausa verbal tindakan bersasaran. Berikut identifikasi komponen dari klausa verbal tindakan bersasaran.

Tabel 3. Klausa Verbal Tindakan Bersasaran

\begin{tabular}{|l|l|l|l|}
\hline $\begin{array}{l}\text { Klausa verbal } \\
\text { tindakan } \\
\text { bersasaran data } \\
(22)\end{array}$ & Kesedihan & telah memakan & ulam dan jantung \\
\hline Fungsi & $\mathrm{S}$ & $\mathrm{P}$ & $\mathrm{O}$ \\
\hline Komponen makna & + manusia & $\begin{array}{l}+ \text { tempat } \\
+ \text { manusia }\end{array}$ & $\begin{array}{l}\text { +manusia } \\
+ \text { perasaan } \\
\text { +bagian tubuh }\end{array}$ \\
\hline
\end{tabular}

Berbeda dengan data metafora klausa verbal tindakan tak bersasaran yang tidak menghadirkan fungsi $\mathrm{O}$ sebagai penjelas tambahan fungsi P. Data (22) menghadirkan fungsi $\mathrm{P}$ dengan komponen makna +tindakan dan +sasaran. Dalam hal ini komponen makna yang mengisi fungsi $\mathrm{P}$ harus sejalan dengan komponen makna yang ada pada fungsi $\mathrm{S}$ dan $\mathrm{O}$. Hal yang dibicarakan pada fungi $\mathrm{S}$ yaitu kesedihan seolah-olah bertindak atau beraktivitas layaknya manusia untuk melakukan tindakan makan yang berarti merengut hal yang utama atau paling berharga dalam diri manusia.

\subsubsection{Klausa Verbal Kejadian}

Klausa verba kejadian merupakan klausa yang mewajibkan hadirnya fungsi $\mathrm{S}$ dan $\mathrm{P}$. Fungsi $\mathrm{P}$ verbal berkomponen (+kejadian). Di dalam klausa, fungsi $\mathrm{S}$ berupa nomina yang mengalami kejadian dari fungsi $\mathrm{P}$, sehingga fungsi $\mathrm{S}$ dan $\mathrm{P}$ wajib hadir di dalam klausa tersebut. Dalam roman Layla Majnun ditemukan metafora yang berbentuk klausa verba kejadian. Berikut ini merupakan data metafora yang berpola klausa verba kejadian dari roman Layla Majnun.

(23) Jiwanya menjerit, memanggil nama Layla kekasih yang direnggut dari tangannya ( $L M$, 2001:16).

Pada kalimat (23) jiwanya menjerit merupakan metafora berbentuk klausa verba kejadian. Berikut ini identifikasi data metafora berpola klausa kejadian dalam roman Layla Majnun.

Tabel 4. Klausa Verba Kejadian

\begin{tabular}{|l|l|l|}
\hline $\begin{array}{l}\text { Klausa verba kejadian pada } \\
\text { data (23) }\end{array}$ & Jiwanya & Menjerit \\
\hline Fungsi & $\mathrm{S}$ & $\mathrm{P}$ \\
\hline Komponen makna & +manusia & +kejadian \\
\hline
\end{tabular}


Klausa verbal kejadian pada data (23) tersusun dari predikat verbal yang memiliki komponen makna +kejadian. Fungsi S pada data (23) wajib hadir karena yang mengalami kejadian. jiwanya merupakan nomina yang mengalami kejadian yang disebutkan oleh predikat verbal menjerit sehingga dalam bentuk klausa verbal kejadian tersebut dapat dimaknai bahwa jiwa atau perasaannya telah tersakiti.

\subsubsection{Klausa Verbal Keadaan}

Klausa verba keadaan merupakan klausa yang predikat verbalnya memiliki komponen makna +keadaan. Fungsi sintaksis yang muncul hanyalah fungsi $\mathrm{S}$ dan P. Fungsi $S$ sebagai nomina yang mengalami keadaan seperti yang telah disebutkan oleh fungsi $\mathrm{P}$, seperti pada kalimat berikut ini.
(24) Karena hujan dapat menghidupkan pohon yang jiwanya layu (LM, 2001:36).

(25) Namun sekarang, harapan itu telah padam, hati mereka hancur binasa melihat putera kesayangan yang diimpikan sepanjang petang dan dibelai sayang sepanjang siang, menderita seperti ini (LM, 2001:47).

(26) Qays sendiri sejak pertama kali melihat pancaran cahaya keindahan itu, jiwanya langsung bergetar ( $L M$, 2001:10).

(27) Namun jiwaku yang telah terbakar rindu belum sembuh jua (LM, 2001:42).

Berikut ini identifikasi data metafora berpola klausa verba keadaan.

Tabel 5. Klausa Verba Keadaan

\begin{tabular}{|l|l|l|}
\hline \multirow{4}{*}{$\begin{array}{l}\text { Klausa verba keadaan pada } \\
\text { kalimat (24), (25), (26), dan (27) }\end{array}$} & Jiwanya & Layu \\
\cline { 2 - 3 } & Harapan itu & telah padam \\
\cline { 2 - 3 } & Jiwaku & langsung bergetar \\
\hline Fungsi & $\mathrm{S}$ & yang telah terbakar \\
\hline Komponen makna & & $\mathrm{P}$ \\
\hline
\end{tabular}

Pada data (24) layu, (25) telah padam, (26) langsung bergetar, (27) yang telah terbakar merupakan pengisi fungsi $\mathrm{P}$ dengan komponen makna +keadaan sedangkan fungsi $\mathrm{S}$ pada data (23) jiwanya, (24) harapan itu, (25) jiwanya, (26) jiwaku merupakan nomina yang mengalami keadaan yang telah disebutkan pada fungsi $P$. Nomina-nomina pengisi fungsi $S$ atau hal yang dibicarakan dalam kontruksi metafora dikenai tindakan atau citranya untuk memberikan gambaran keadaan yang lebih konkret dalam mendeskripsikan sebuah kesedihan yang mengenai diri manusia.

\section{Kesimpulan}

Berdasarkan analisis klasifikasi struktur metafora di dalam roman Layla
Majnun, dapat disimpulkan bahwa struktur metafora yang digunakan di dalam roman Layla Majnun berupa frase dan klausa. Bentuk Frasa dapat klasifikasikan menjadi Frasa Nomina dan perluasan frasa. FN terdiri atas beberapa unsur yang berbeda, antara lain: FN yang berpola $\mathrm{N}+\mathrm{N}$ dan $\mathrm{FN}$ berpola $\mathrm{N}+\mathrm{V}$, sedangkan dalam bentuk klausa terdapat bentuk klausa nominal dan klausa verbal. Pada klausa verbal dapat diklasifikasikan kembali menjadi klausa verbal tindakan tak bersasaran, klausa verbal bersasaran, klausa verbal kejadian dan klausa verbal keadaan. Bentuk frasa nomina dan verba dipilih untuk mengkonkretkan citra. Selain itu, bentuk klausa nominal dan verbal yang secara gramatikal lebih panjang dan 
luas daripada bentuk frasa, membantu memperjelas makna yang akan diungkapkan dalam citra dari sebuah kontruksi metafora.

\section{Daftar Pustaka}

Alwi, H, dkk. 2017. Tata Bahasa Baku Bahasa Indonesia edisi keempat. Badan Pengembangan dan Pembinaan Bahasa.

Arianto, A. K. (2018). "Medan Makna Pembentuk Metafora dalam Syair Arab." Widyaparwa, 46(2), 112125.

Chaer, A. 2015. Sintaksis Bahasa Indonesia. Rineka Cipta.

Firman, D., and K. B. S. T. (2016). "Klasifikasi dan analisis klausa bahasa culumbatu". Kandai, 12(2), 187-203.

Knowles, M. \& M. R. 2005. Introducing Metaphor (1st ed.). Routledge. https://doi.org/https://doi.org/10.432 4/9780203642368

Kridalaksana, H. 2008. Kamus Linguistik (4th ed.). Jakarta: Gramedia Pustaka
Utama.

Mahur, F. B. A. (2019). "Artikel Metafora Antropomorfis Sebagai Lambang Identitas Kultural Masyarakat Sabu". Jurnal Lazuardi, 2(2), 239-256.

Parera, J. D. 2004. Teori Semantik (2nd ed.). Jakarta: Erlangga.

Sasangka, S. S. T. W. 2014. Kalimat. Pusat Pembinaan dan Pemasyarakatan Badan Pengembangan dan Pembinaan Bahasa Kementerian Pendidikan dan Kebudayaan.

Setiaji, A. B., Jufri, J., \& Nensilianti, N. 2018. Struktur Frasa Metafora Dalam Wacana Narasi Kajian Semantik. Universitas Negeri Makassar.

Setiaji, A. B. (2019). "Struktur Metafora Pada Kumpulan Puisi Tidak Ada New York Hari Ini Karya M. Aan Mansyur". Sasindo, 7(1).

Wahab, A. (1991). Isu linguistik: Pengajaran bahasa dan sastra. Surabaya: Airlangga University Press. 